\title{
KAPPA OPIOID RECEPTOR BLOCKADE IN NAc SHELL PREVENTS SEX-DEPENDENT ALCOHOL RELAPSE-LIKE BEHAVIOUR INDUCED BY INFLAMMATORY PAIN.
}

\author{
Jesús Lorente $^{1}$, Javier Cuitavi ${ }^{1}$, Yolanda Campos ${ }^{1}$, Raquel Montón-Molina ${ }^{1}$, Jose \\ González-Romero ${ }^{1}$, and Lucia Hipolito ${ }^{1}$ \\ ${ }^{1}$ University of Valencia
}

October 25, 2020

\begin{abstract}
Background and Purpose Pain-induced negative affect reduces life quality of patients by increasing psychiatric comorbidities, including alcohol use disorders (AUD). Indeed, clinical data suggest pain as a risk factor to suffer AUD, predicting relapse drinking in abstinent patients. Here, we analyse the impact of pain on alcohol relapse and the role of kappa opioid receptors (KOR) activation in mediating this pain-induced effects since KOR play an important role in pain-driven negative affect and AUD. Experimental approach Female and male Sprague Dawley rats underwent to two alcohol intermittent access periods separated by a forced abstinence period. The complete Freund adjuvant (CFA) model of inflammatory pain was introduced during abstinence and alcohol intake after alcohol reintroduction was assessed. Additionally, we used behavioural approaches to measure stress and memory impairment and biochemical assays to measure KOR expression in abstinence and reintroduction periods. Finally, KOR antagonist norbinaltorphimine (norBNI) was administered in the nucleus accumbens shell (NAcS) during abstinence to prevent pain-induced alcohol relapse-like phenomenon in CFA-female rats. Key results Only female CFA-treated rats increased alcohol intake during reintroduction period. Concomitantly, this group showed enhanced stress-like behaviour and increased KOR expression in the NAcS that was developed during abstinence and remained during reintroduction period. Finally, norBNI administered in the NAcS prevented pain-induced alcohol relapse-like behaviour in female rats. Conclusions and implications Our data evidenced that inflammatory pain constitutes a risk factor to relapse only in female rats, by the arise and maintenance of stress probably mediated by kappa opioid receptor (KOR) signaling in the NAcS.
\end{abstract}

\section{Hosted file}

manuscript_221020_revisionfinal.pdf available at https://authorea.com/users/369978/articles/ 488771-kappa-opioid-receptor-blockade-in-nac-shell-prevents-sex-dependent-alcohol-

relapse-like-behaviour-induced-by-inflammatory-pain 
FIGURE 1.
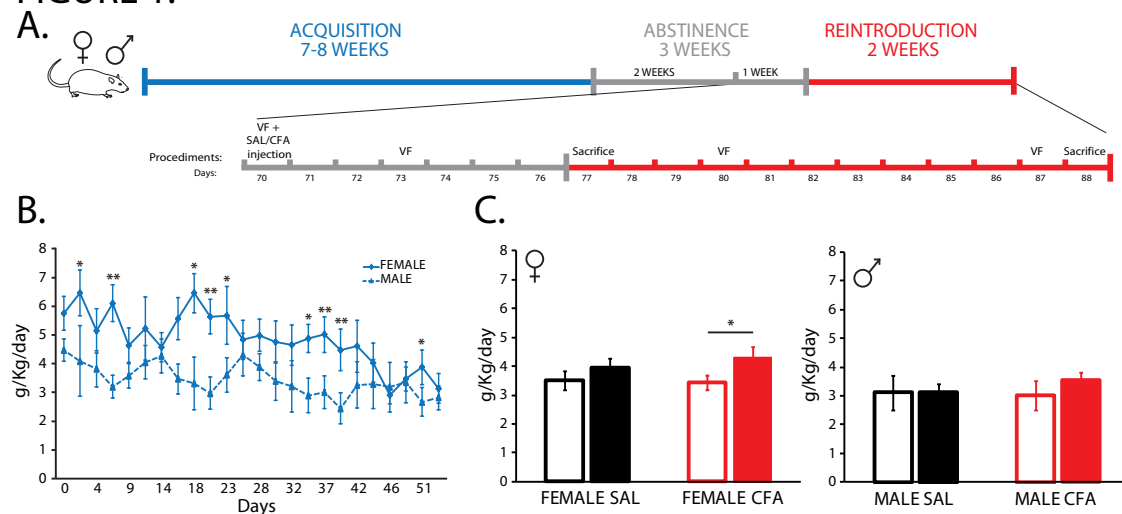

C.

D.
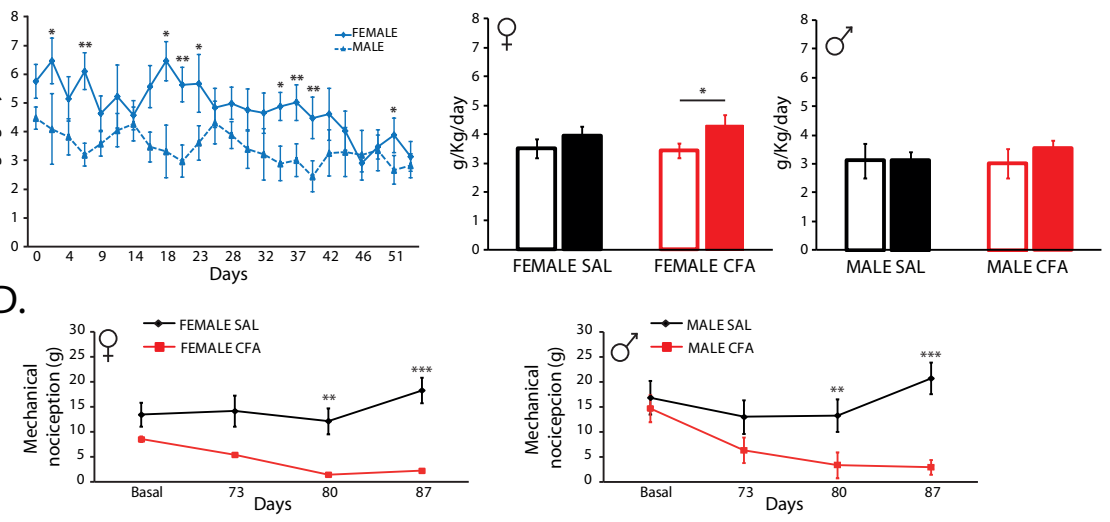

E.

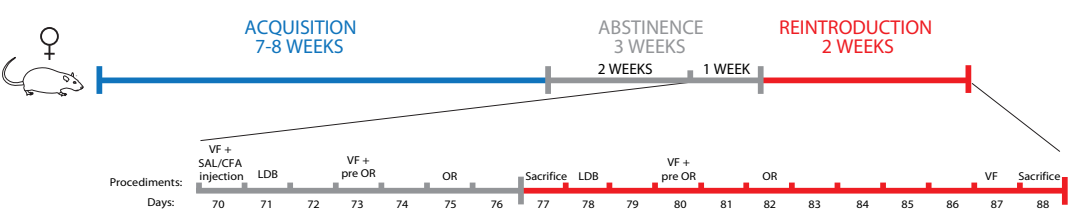

F.

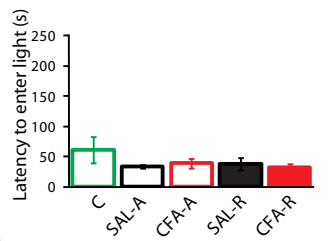

I.

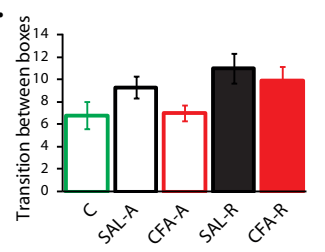

G.

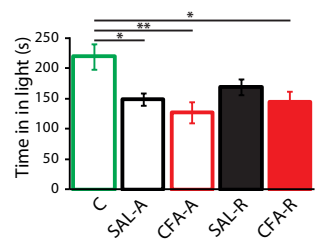

J.

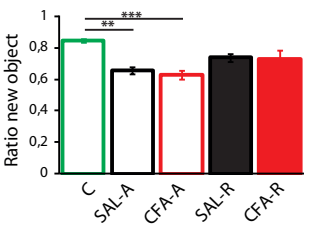

$\mathrm{H}$.

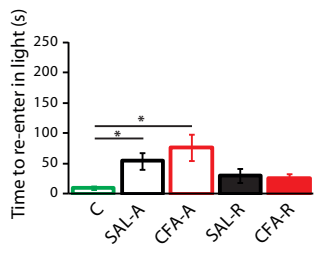


FIGURE 2.

A. NAc MALE
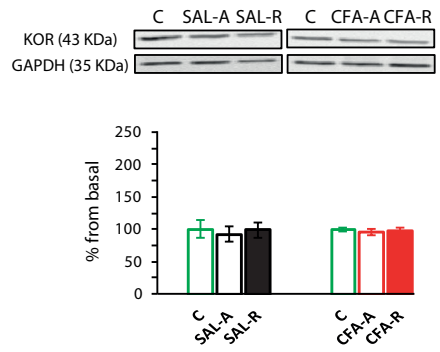

C. PFC MALE
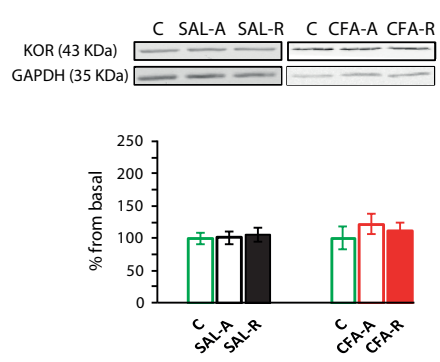

E. AMYGDALA MALE
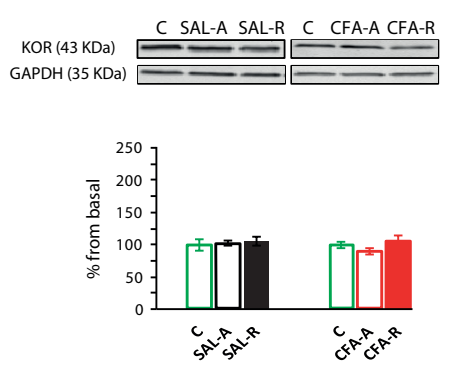

B. NAC FEMALE

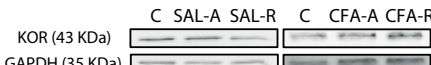

GAPDH (35 KDa) —

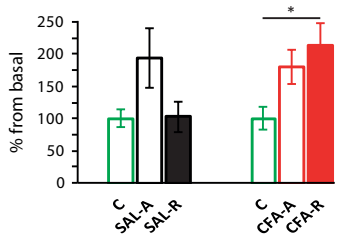

D. PFC FEMALE
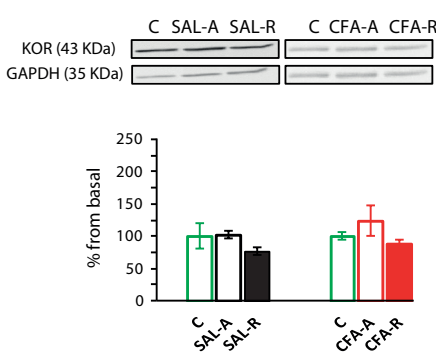

F. AMYGDALA FEMALES

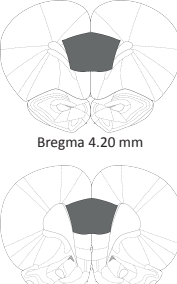

KOR (43 KDa)
GAPDH (35 KDa)

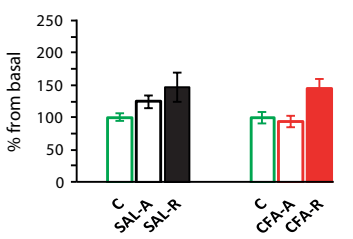

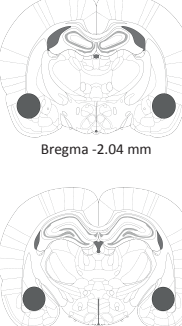

Bregma $-3.24 \mathrm{~mm}$

\section{Hosted file}

Figure 3.pdf available at https://authorea.com/users/369978/articles/488771-kappa-opioidreceptor-blockade-in-nac-shell-prevents-sex-dependent-alcohol-relapse-like-behaviourinduced-by-inflammatory-pain 
FIGURE 4.

A.

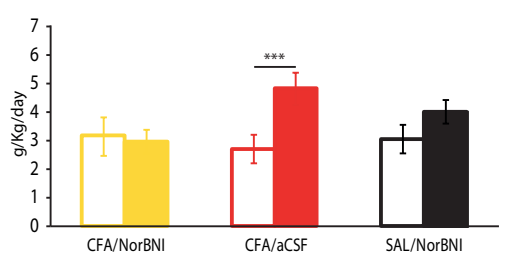

B.

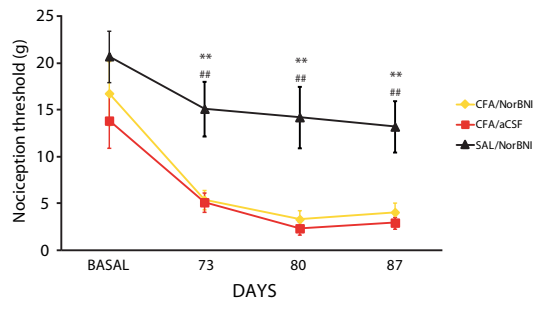

